\title{
Uncertainty Estimation of Drone Propellers Acceleration and Stability
}

\author{
Darmeli Nasution ${ }^{1}$, Donni Nasution ${ }^{2}$, Andysah Putera Utama Siahaan ${ }^{3}$ \\ ${ }^{1,3}$ Faculty of Computer Science \\ ${ }^{1,3}$ Universitas Pembangunan Panca Budi \\ ${ }^{2}$ Akademik Manajemen Informatika dan Komputer Royal \\ ${ }^{1,3}$ Jl. Jend. Gatot Subroto Km. 4,5 Sei Sikambing, 20122, Medan, Sumatera Utara, Indonesia \\ ${ }^{2}$ Jl. Imam Bonjol No.179, Teladan, Kisaran, Kabupaten Asahan, Sumatera Utara, Indonesia
}

\begin{abstract}
Drones are unmanned aircraft are often used for specific purposes especially in the military environment. The use of these aircraft often experiences problems while in the air. There are two types of machines used in the drone, jet, and propeller. This study aims at the use of propellers. Usually, the drone has four propellers on each side, but there also has more. Load changes will affect the balance of drones. It will also change the angle of each side. Fuzzy techniques applied in this case is that it will adjust the speed of each propeller based on the load that it has. Every corner will affect the balance are two points $X$ and $Y$. The application of this method will improve the speed of the propeller and made the position of drones in the air to be stable.
\end{abstract}

Index Terms — Fuzzy, Sugeno, Drone, Stability

\section{INTRODUCTION}

A drone is a flying machine controlled remotely by the pilot or could fly at all without a pilot (autopilot). Drone uses aerodynamics to raise itself. It can be occupied to carry payloads either weapons or other cargo and even photography equipment. The greatest use of the unmanned aircraft is in the military field. When carrying the hard material, the drone does not always put the load in the middle of the body. Sometimes it is aligned to the corner. The stability depends on the speed of propellers. The common drone has four propellers. There are also has six or eight propellers. Every side of the propeller has its strength. Once the things are loaded, the speed must gain. If not, the drone will tilt down or even crash [8]. The problem is how to make the drone stable when there is a disruption. The crisp decision cannot be implemented to this situation. It needs a smooth movement where the crisp itself cannot perform it. The goal is to determine the acceleration using fuzzy estimation [7, 9]. A Fuzzy method is one of the uncertainties expected methods to solve the certain problems [10]. The output hope is that it can predict the speed changes by such parameters.

\section{THEORIES}

The quadcopter has four propellers propulsion that is perpendicular to the plane $[1,3,6]$. Control and stability of this flying machine are possible by changing the engine RPM. High maneuverability, the short time needed for learning piloting which takes a few days, the simplicity of construction, low maintenance costs and low noise are the advantages of this unique flying machine compared to the other similar unmanned flying machines [4]

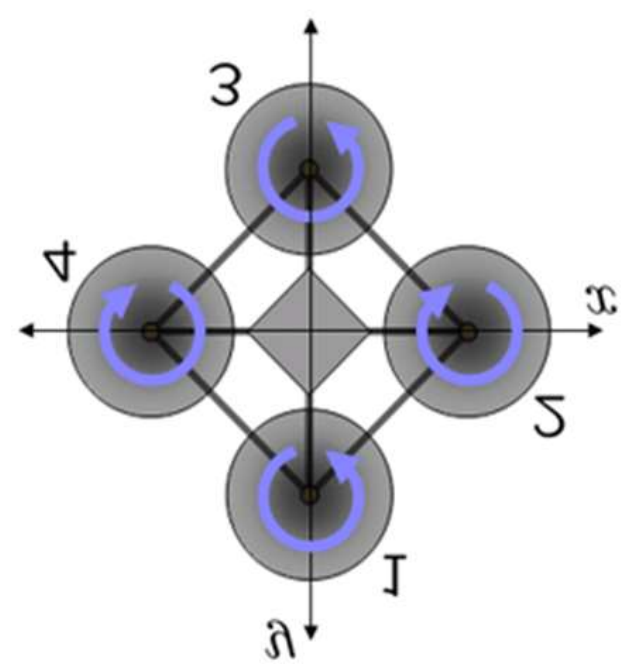

Fig. 1 Quadcopter propellers direction 
Each rotor generates lift and has the same distance to the center of drones. With great power, it allows Quadcopter to fly. Quadrotor speed depends on the motor power and weight quadrotor itself. To avoid a torque on the body, the direction of rotation blades on each rotor is different. There are two rotors that move clockwise direction while the others move counterclockwise.Figure 1 show the direction of each propller. Propeller 1 and 3 moves clockwise direction. Propeller 2 and 4 moves counter-clockwise. It is to avoid the plane crash and unstable. The most common configuration used is X-quadcopter. When quadcopter is flying and hovering, each rotor rotating speed is same. When quadcopter moves forward, two pieces of the rear propeller will spin faster so the body quadcopter will tilt forward. The thrust has the four propellers move upward and forward so quadcopter will be pushed toward the front while maintaining its altitude. The following figure is an illustration of air movement influenced by the speed of the propeller.

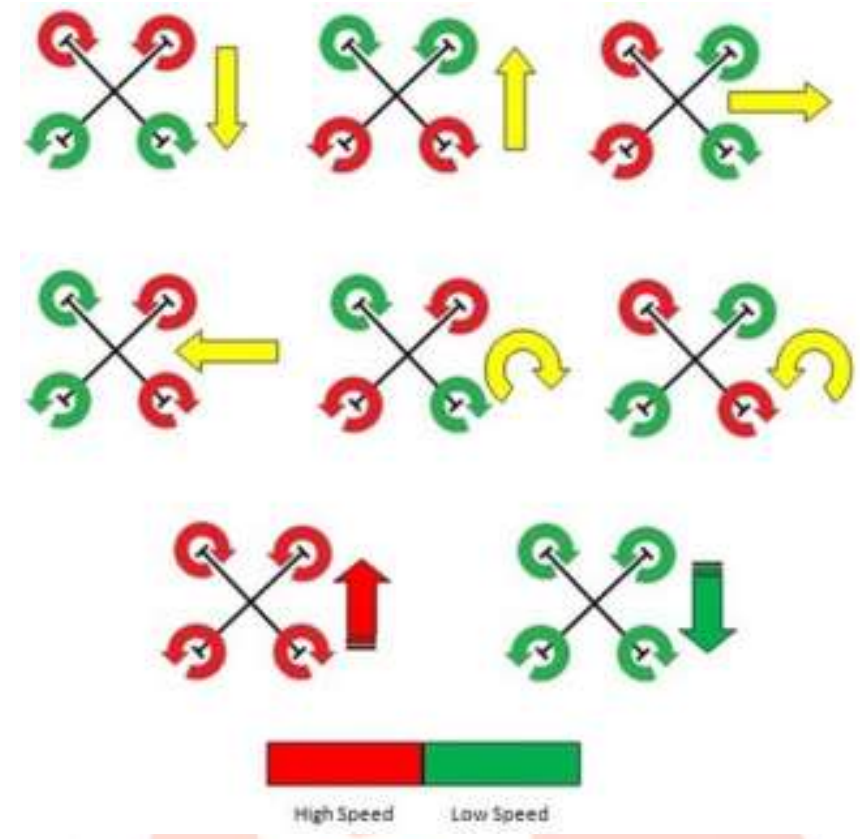

Fig. 2 Quadcopter movements

The motion along any direction on the lateral axis is obtained by decreasing the rotational speed of the rotors along the desired direction of motion, and increasing the rotational speed of the rotors opposite to the desired direction of motion [5]. Figure 2 explains the direction based on the speed of propellers. There are two categories, high and low speed. Although there are only two categories, each of them is divided into a range of speed depends on the weight loaded. To move to a specific direction, two propellers must rotate at high speed to push the drone to its desired direction.

\section{Proposed Work Concept}

The concept is to create three variables affection the propeller acceleration. There are tilt and load. The first parameter is divided into two axes such as X and Y. The other parameter is a load. It represents the weight hold. Every membership function will give the range of the variable position. The initial propeller rotation per minute is adjustable, and it depends on the drone weight. This research excludes the physics law to determine the speed based on air pressure, weight, gravity, and other aspects. There only tilt and load and are manually inputted.

There are four input parameters used:

$$
\begin{array}{ll}
\text { - } & \text { Speed } \\
\text { - } & \text { Tilt X } \\
\text { - } & \text { Tilt Y } \\
\text { - } & \text { Load }
\end{array}
$$

There are four output parameters:

- $\quad$ Speed of Propeller Number 1 (rpm)

- $\quad$ Speed of Propeller Number 2 (rpm)

- $\quad$ Speed of Propeller Number $3(\mathrm{rpm})$

- $\quad$ Speed of Propeller Number 4 (rpm)

Speed is the initial propeller rotation per minute, but it is not included in the fuzzy calculation. The output consists of four speeds. There will be not identical. When using more than four propellers, the output must consist of more output as well. 


\section{Membership Function}

This section explains the use of membership function. There are three kinds involved in this research. Each membership function has its value and region.

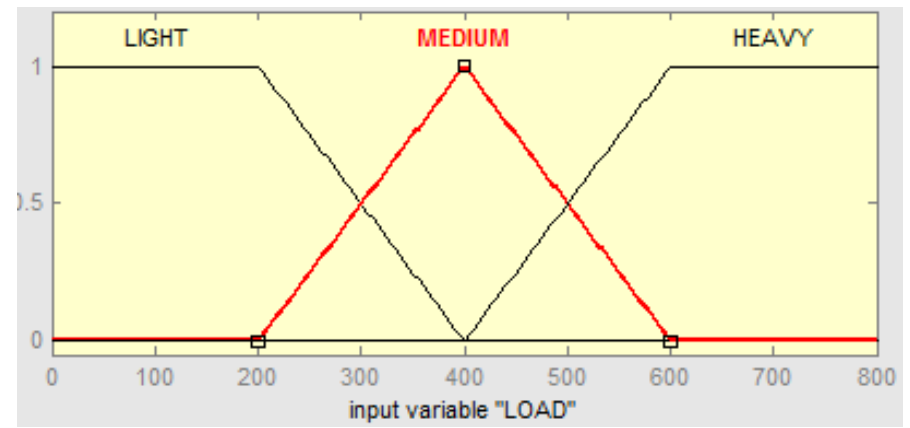

Fig. 3 LOAD membership function

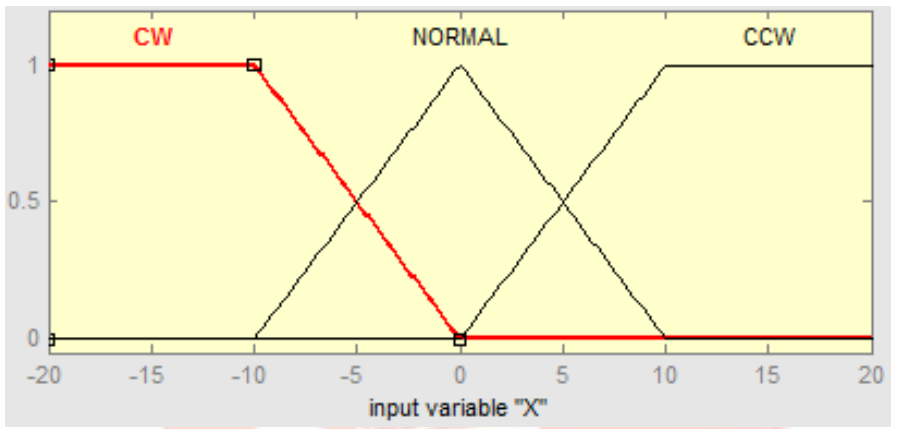

Fig. 4 TILT X membership function

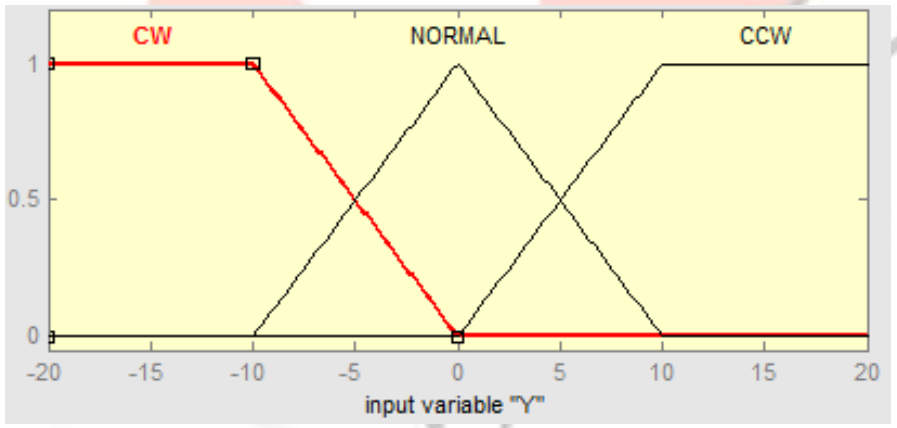

Fig. 5 TILT Y membership function

Figure 3 to 5 describe the division of the membership function. The LOAD consists of three parts, LIGHT (0;200;400), MEDIUM (200;400;600) and HEAVY (400;600;800). The limit is determined by users. The X and Y have the same content; CW $(-20,-10,0)$, NORMAL $(-10,0,10)$ and $\operatorname{CCW}(0,10,20)$.

\section{Fuzzy Rules}

A fuzzy rule is the mapping process from input to output using fuzzy estimation, and it provides a decision or pattern discerned. The process involves logical operations, and If-Then Rules [2]. The output in the fuzzy rule is based on the perception. It is adjustable. When the change is needed, it can be modified all the time. In Table 1, fuzzy rules produce four outputs. There are MOTOR 1, MOTOR 2, MOTOR 3, and MOTOR 4. They describe the speed of the propellers. Each motor has the specific value. Sometimes they can be similar. It depends on the tilt and load. There are 27 rules created. This value is obtained from $3 \mathrm{x}$ 3 membership functions. Each variable consists of three ranges. The first membership function, LOAD, has three parts, LIGHT, MEDIUM and HEAVY. The second, TILT X, has three parts, CW, NORMAL and CCW while the last, TILT Y has tree as well, CW, NORMAL and CCW. 
Table 1 Fuzzy Rules

\begin{tabular}{|c|c|c|c|c|c|c|c|}
\hline RULE & LOAD & $\mathbf{Y}$ & $\mathbf{x}$ & $\begin{array}{c}\text { MOTOR } \\
1\end{array}$ & $\begin{array}{c}\text { MOTOR } \\
2\end{array}$ & $\begin{array}{c}\text { MOTOR } \\
\mathbf{3}\end{array}$ & $\begin{array}{c}\text { MOTOR } \\
4\end{array}$ \\
\hline 1 & LIGHT & $\mathrm{CW}$ & $\mathrm{CW}$ & SLOW & SLOW & FIXED & FIXED \\
\hline 2 & LIGHT & $\mathrm{CW}$ & NORMAL & FIXED & SLOW & FIXED & FIXED \\
\hline 3 & LIGHT & $\mathrm{CW}$ & $\mathrm{CCW}$ & FIXED & SLOW & SLOW & FIXED \\
\hline 4 & LIGHT & NORMAL & $\mathrm{CW}$ & SLOW & FIXED & FIXED & FIXED \\
\hline 5 & LIGHT & NORMAL & NORMAL & FIXED & FIXED & FIXED & FIXED \\
\hline 6 & LIGHT & NORMAL & $\mathrm{CCW}$ & FIXED & FIXED & SLOW & FIXED \\
\hline 7 & LIGHT & $\mathrm{CCW}$ & $\mathrm{CW}$ & SLOW & FIXED & FIXED & SLOW \\
\hline 8 & LIGHT & $\mathrm{CCW}$ & NORMAL & FIXED & FIXED & FIXED & SLOW \\
\hline 9 & LIGHT & $\mathrm{CCW}$ & $\mathrm{CCW}$ & FIXED & FIXED & SLOW & SLOW \\
\hline 10 & MEDIUM & $\mathrm{CW}$ & $\mathrm{CW}$ & AVG & AVG & SLOW & SLOW \\
\hline 11 & MEDIUM & $\mathrm{CW}$ & NORMAL & SLOW & $\mathrm{AVG}$ & SLOW & SLOW \\
\hline 12 & MEDIUM & $\mathrm{CW}$ & $\mathrm{CCW}$ & SLOW & $\overline{A V G}$ & AVG & SLOW \\
\hline 13 & MEDIUM & NORMAL & $\mathrm{CW}$ & AVG & SLOW & SLOW & SLOW \\
\hline 14 & MEDIUM & NORMAL & NORMAL & SLOW & SLOW & SLOW & SLOW \\
\hline 15 & MEDIUM & NORMAL & $\mathrm{CCW}$ & SLOW & SLOW & AVG & SLOW \\
\hline 16 & MEDIUM & $\mathrm{CCW}$ & $\mathrm{CW}$ & AVG & SLOW & SLOW & AVG \\
\hline 17 & MEDIUM & $\mathrm{CCW}$ & NORMAL & SLOW & SLOW & SLOW & AVG \\
\hline 18 & MEDIUM & $\mathrm{CCW}$ & $\mathrm{CCW}$ & SLOW & SLOW & AVG & AVG \\
\hline 19 & HEAVY & $\mathrm{CW}$ & $\mathrm{CW}$ & FAST & FAST & AVG & AVG \\
\hline 20 & HEAVY & $\mathrm{CW}$ & NORMAL & $\mathrm{AVG}$ & FAST & AVG & AVG \\
\hline 21 & HEAVY & $\mathrm{CW}$ & CCW & AVG & FAST & FAST & AVG \\
\hline 22 & HEAVY & NORMAL & $\mathrm{CW}$ & FAST & AVG & AVG & AVG \\
\hline 23 & HEAVY & NORMAL & NORMAL & $\mathrm{AVG}$ & AVG & AVG & AVG \\
\hline 24 & HEAVY & NORMAL & $\mathrm{CCW}$ & AVG & $\mathrm{AVG}$ & FAST & AVG \\
\hline 25 & HEAVY & CCW & $\mathrm{CW}$ & FAST & AVG & AVG & FAST \\
\hline 26 & HEAVY & $\mathrm{CCW}$ & NORMAL & AVG & $\mathrm{AVG}$ & $\mathrm{AVG}$ & FAST \\
\hline 27 & HEAVY & $\mathrm{CCW}$ & $\mathrm{CCW}$ & AVG & $\mathrm{AVG}$ & FAST & FAST \\
\hline
\end{tabular}

\section{Output}

This following sample illustrates the calculation to find the acceleration. It describes in percentage. Acceleration is the increase in the speed of the previous speed. Table 2 shows the output range of the propellers power.

Table 2 Output of the propeller acceleration

\begin{tabular}{|c|c|c|}
\hline OUTPUT & FROM & TO \\
\hline FIXED & $0 \%$ & $0 \%$ \\
\hline SLOW & $1 \%$ & $20 \%$ \\
\hline AVERAGE & $21 \%$ & $30 \%$ \\
\hline FAST & $31 \%$ & $40 \%$ \\
\hline
\end{tabular}

The calculation:

$\begin{array}{lll}\text { LOAD } & : & 30 \\ \mathrm{X} & : & -2 \\ \mathrm{Y} & : & 12\end{array}$

\section{LOAD}

$\mu_{\text {LIGHT }}(30)=1$

$\mu_{\text {MEDIUM }}(30)=0$

$\mu_{\text {HEAVY }}(30)=0$ 


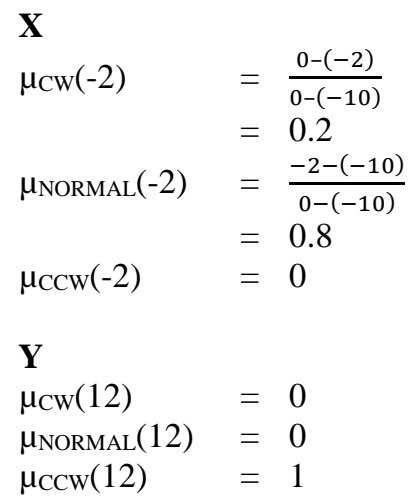

\section{[R1] IF LOAD $=\mathrm{LIGHT}$ AND $\mathrm{Y}=\mathrm{CCW}$ AND $\mathrm{X}=\mathrm{CW}$ THEN MOTOR $=\mathrm{SLOW}$}

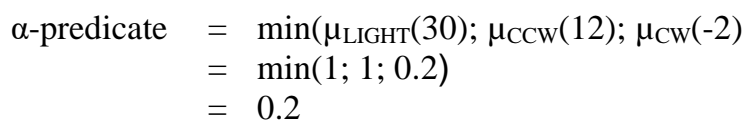

\section{[R2] IF LOAD=LIGHT AND Y=CCW AND X=NORMAL THEN MOTOR=FIXED}

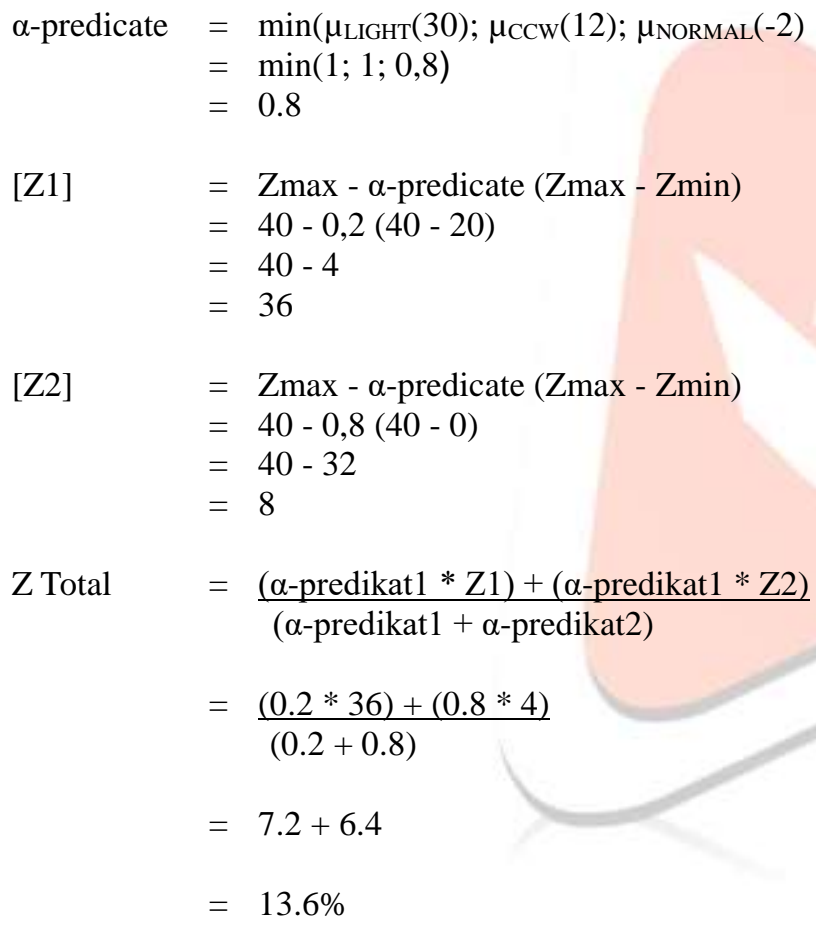

The above calculation produces $13.6 \%$ acceleration. It will increase the propeller by $13.6 \%$ from the current speed. The value is between FIXED and SLOW (Table 2). It happens since the rules elected consists of FIXED and SLOW only. The resulting probability is similar to the input range as well.

\section{Evaluation}

This section will demonstrate the calculation of fuzzy Tsukamoto in controlling the propellers speed. The following data is used as the initial inputs. The numbers inserted into the variables are random as long as in the range determined earlier.

$\begin{array}{ll}\text { SPEED } & =20000 \mathrm{rpm} \\ \text { LOAD } & =550 \mathrm{gr} \\ \text { TILT X AXIS } & =8^{\circ} \\ \text { TILT Y AXIS } & =5^{\circ}\end{array}$


Table 3 LOAD membership function area

\begin{tabular}{|l|l|l|c|}
\hline \multicolumn{5}{|c|}{ I } & \multicolumn{1}{c|}{ II } & III \\
\hline LIGHT & 0 & 200 & 400 \\
\hline MEDIUM & 200 & 400 & 600 \\
\hline HEAVY & 400 & 600 & 800 \\
\hline
\end{tabular}

Table 3 shows the limitation of the LOAD parameter. The initial input is 500. It is between MEDIUM and HEAVY. The maxium value is 800 . It is divided into three parts $(0-200-400-600-800)$ and up to a desired.

$$
\begin{aligned}
\mu \text { LIGHT } & =0 \\
\mu \text { MEDIUM } & =\frac{600-550}{600-400} \\
& =\frac{50}{200} \\
& =0.25 \\
\mu \text { MEDIUM } & =\frac{550-400}{600-400} \\
& =\frac{150}{200} \\
& =0.75
\end{aligned}
$$

Table 4 TILT X Axis membership function area

\begin{tabular}{|l|r|r|r|}
\hline \multicolumn{4}{|c|}{ TILT X AXIS } \\
\hline & \multicolumn{1}{|c|}{ I } & \multicolumn{1}{c|}{ II } & \multicolumn{1}{c|}{ III } \\
\hline CW & $-20^{\circ}$ & $-10^{\circ}$ & $0^{\circ}$ \\
\hline NORMAL & $-10^{\circ}$ & $0^{\circ}$ & $10^{\circ}$ \\
\hline CCW & $0^{\circ}$ & $10^{\circ}$ & $20^{\circ}$ \\
\hline
\end{tabular}

Tabel 4 show the tilt of the $\mathrm{X}$ axis. It is devided into three section as well. The initial input is $8^{\circ}$. It is between NORMAL and CCW.

$$
\begin{aligned}
\mu \mathrm{CW} & =0 \\
\mu \mathrm{NORMAL} & =\frac{10-8}{10-0} \\
& =\frac{2}{10} \\
& =0.2 \\
\mu \mathrm{CCW} & =\frac{8-0}{10-0} \\
& =\frac{8}{10} \\
& =0.8
\end{aligned}
$$

Table 5 TILT X Axis membership function area

\begin{tabular}{|l|r|r|r|}
\hline \multicolumn{4}{|c|}{ TILT Y AXIS } \\
\hline & \multicolumn{1}{|c|}{ I } & \multicolumn{1}{c|}{ II } & \multicolumn{1}{c|}{ III } \\
\hline CW & $-20^{\circ}$ & $-10^{\circ}$ & $0^{\circ}$ \\
\hline NORMAL & $-10^{\circ}$ & $0^{\circ}$ & $10^{\circ}$ \\
\hline CCW & $0^{\circ}$ & $10^{\circ}$ & $20^{\circ}$ \\
\hline
\end{tabular}

Tabel 5 show the tilt of the $\mathrm{X}$ axis. It is devided into three section as well. The initial input is $5^{\circ}$. It is between NORMAL and CCW. 


$$
\begin{aligned}
\mu \mathrm{CW} & =0 \\
\mu \mathrm{NORMAL} & =\frac{10-5}{10-0} \\
& =\frac{5}{10} \\
& =0.5 \\
\mu \mathrm{CCW} & =\frac{5-0}{10-0} \\
& =\frac{5}{10} \\
& =0.5
\end{aligned}
$$

There are six sections which values are not zero. It means there are eight rules $(2 \times 2 \times 2)$ involved in the fuzzy inference. There are $\{$ Load : $\mu$ MEDIUM, $\mu$ HEAVY $\},\{$ Tilt $X: \mu$ NORMAL, $\mu$ CCW $\}$, and $\{$ Tilt $Y: \mu$ NORMAL, $\mu C C W\}$.

The following rules explain the calculation of the above data

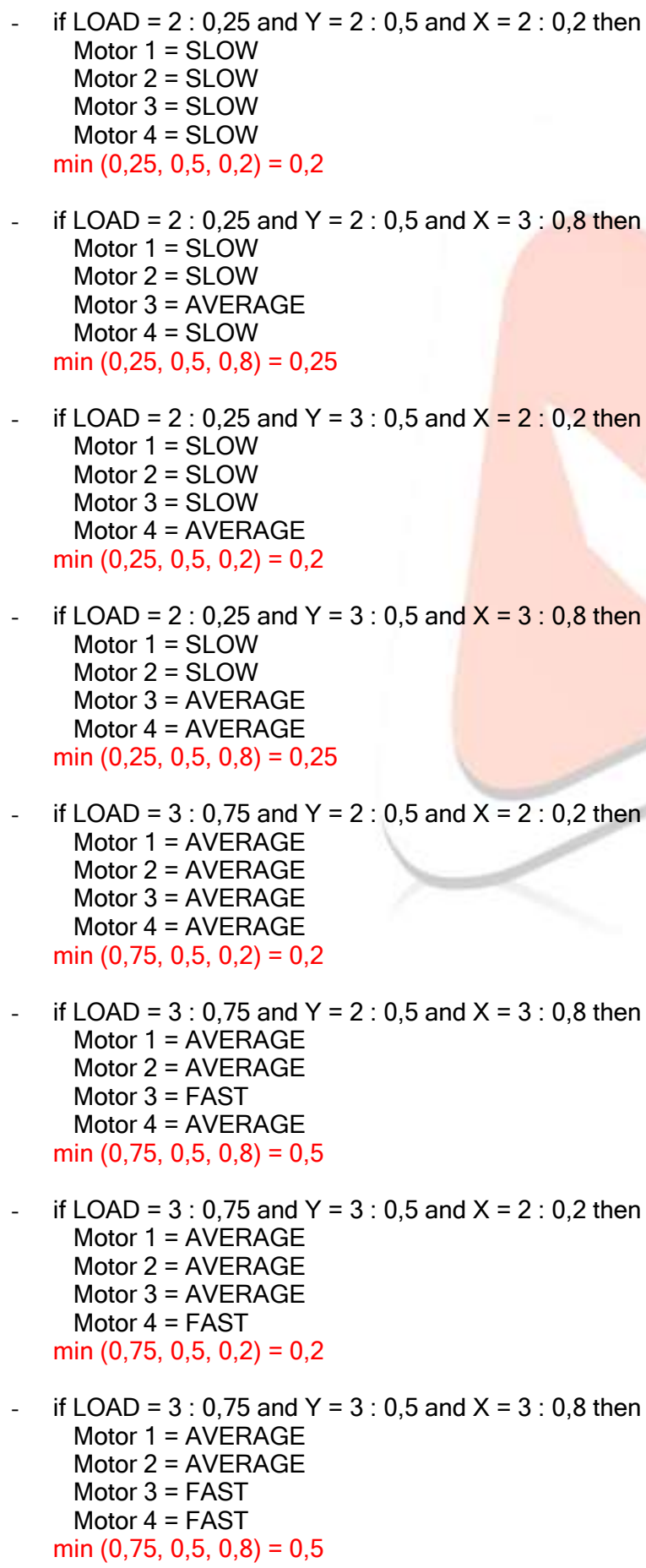


Table 5 show the final calculation of the fuzzy estimations. The propeller of MOTOR 3 is the fastest (38,413\%) because TILT $\mathrm{X}$ value is bigger than TILT Y value. It made the drone leaning to a particular direction. The propellers of MOTOR 1 and 2 have the same value $(35,696 \%)$. They run to maintain the position. The MOTOR 4 propeller is rather big than the MOTOR 1 and 2 propellers.

Table 5 Propellers speed output

\begin{tabular}{|c|c|c|}
\hline OUTPUT & ACC. & RPM \\
\hline MOTOR 1 & $35,696 \%$ & 27.140 \\
\hline MOTOR 2 & $35,696 \%$ & 27.140 \\
\hline MOTOR 3 & $38,413 \%$ & 27.683 \\
\hline MOTOR 4 & $37,402 \%$ & 27.481 \\
\hline
\end{tabular}

\section{CONCLUSION}

The objective of this research was to simulate the fuzzy speed controller for the drone. Initially, the variables cover three parameters, LOAD, TILT X, and TILT Y. The experiments to validate the functionality of the balancing controller performed to avoid the major technical difficulties. Despite major technical problems, the research got the satisfactory results. It concludes that it is possible to control the balancing with fuzzy estimation. The propellers speed can be adjusted to the situation around the drone. It analyzes the weight loaded, and the tilt of two axes. The fuzzy will fix the balance error of the drone. There is no guarantee that the estimation is the best. However, it is impossible to compare the results with the other existing research approaches as the experimentation was done in highly constrained setup. The further works will be required once the issues raise.

\section{FUTURE SCOPE}

As discussed earlier, the initial goal of this research is to balance the drone while it is in the air. Unfortunately, the calculation is not based on physics law. The input speed needs to be determined automatically. It must calculate the drone weight (without anything hanging) and adjust the initial speed properly. Afterward, the indoor GPS is more likely. The drone is expected to maneuver automaticly and the fuzzy control the power based on the input parameters affected.

\section{REFERENCES}

[1] F. Ikhsan, "Mengenal Dasar-dasar Quadcopter," 157 2014. [Online]. Available: http://firmanikhsan.com/ mengenalquadcopter/. [Accessed 107 2016].

[2] MathWorks, "Fuzzy Inference Process," [Online]. Available: http://www.mathworks.com/help/fuzzy/fuzzy -inferenceprocess.html. [Accessed 117 2016].

[3] A. S. K. Anjuml, R. A. Sufian, Z. Abbas and I. M. Qureshi, "Attitude Control of Quadcopter Using Adaptive Neuro Fuzzy Control," International Journal of Hybrid Information Technology, vol. 9, no. 4, pp. 139-150, 2016.

[4] E. A. Seidabad, S. Vandaki and A. V. Kamyad, "Designing Fuzzy PID Controller for Quadrotor," International Journal of Advanced Research in Computer Science \& Technology, vol. 2, no. 4, pp. 221-227, 2014.

[5] D. Gautam and C. Ha, "Control of a Quadrotor Using a Smart Self-Tuning Fuzzy PID Controller," International Journal of Advanced Robotic Systems, vol. 10, no. 380, pp. 1-9, 2013.

[6] P. Benavidez, J. Lambert, A. Jaimes and M. Jamshidi, "Landing of An Ardrone 2.0 Quadcopter on A Mobile Base," International Journal of Complex Systems - Computing, Sensing and Control, vol. 1, no. 2, pp. 5-25, 2013.

[7] F. A. T. Al-Saedi and R. A. Sabar, "Design and Implementation of Autopilot System for Quadcopter," International Journal of Computer Science Engineering and Technology, vol. 5, no. 6, pp. 90-199, 2015.

[8] M. Khan, "Quadcopter Flight Dynamics," International Journal Of Scientific \& Technology Research, vol. 3, no. 8, pp. 130-135, 2014.

[9] A. Prayitno, V. Indrawati and G. Utomo, "Trajectory Tracking of AR.Drone Quadrotor Using Fuzzy Logic Controller," Telecommunication, Computing, Electronics and Control, vol. 12, no. 4, pp. 819-828, 2014.

[10] K. Saputra, W. A. Kusuma and A. Buono, "Fuzzy-based Spectral Alignment for Correcting DNA Sequence from Next Generation Sequencer," Telecommunication, Computing, Electronics and Control, vol. 14, no. 2, pp. 707-714, 62016. 